\title{
Life extension, human rights, and the rational refinement of repugnance
}

\section{A D N J de Grey}

\section{On the ethics of extending human life: healthy people have a right to carry on living}

$\mathrm{H}$ umanity has long demonstrated a paradoxical ambivalence concerning the extension of a healthy human lifespan. Modest health extension has been universally sought, whereas extreme (even indefinite) health extension has been regarded as a snare and delusion - a dream beyond all others at first blush, but actually something we are better off without. The prevailing pace of biotechnological progress is bringing ever closer the day when humanity will be able to act on the latter view by rejecting a clear and present opportunity for much longer healthy lives. Indeed, some biogerontologists (including myself) contend that that day has already arrived, to the extent that our hesitation in embarking on a vigorous "war on ageing" is already delaying the point at which a cure for ageing will be developed. Here I consider whether our present caution concerning the wisdom of truly curing ageing is likely to survive the increased scrutiny that it will receive in coming years as a result of these technical advances. I conclude that it will not, because of its irreconcilability with values that are more deeply held by the large majority of humanity than any values that argue against the quest for a cure. I further conclude that all the major current reasons given for not curing ageing are mere crutches to help us cope with the immutability of ageing that we have been brought up to accept. Our failure to set aside such irrationality (as it has become with recent advances in biomedical gerontology, even if it was justifiable on psychological grounds hitherto) is already shortening potential longevity-quite probably of those already alive today-to a staggering degree. Once we realise this, our determination to consign human ageing to history will be second only to our shame that we took so long to break out of our collective trance.

\section{BACKGROUND: CRAVEN DISTORTION OF BIOLOGY FOR ILLUSORY POLITICAL GAIN}

Biogerontology is living a lie. The technical term for this lie is "compression of morbidity". It asserts that the ultimate goal of research into the biology of ageing is to increase the average healthy lifespan ("healthspan", as it is commonly termed these days) without appreciably increasing average total lifespan, and thus to shorten the average period of frailty and ill health at the end of life (which I will here call "frailspan"). Generally it is couched in slightly more ambiguous language, such as that an increase in total lifespan is not precisely something to be avoided but is certainly no more than an incidental corollary to increasing healthspan. A typical expression of this ${ }^{1}$ is that biogerontology is focused on "adding life to years, not just years to life".

The motivation for this party line is of course obvious: the desirability of health is uncontroversial, whereas increasing total lifespan conjures up in politicians' minds the scenario that Fukuyama has called $^{2}$ the "global nursing home" in which morbidity is not only not compressed but is expanded, with a greater increase in total lifespan than in healthy lifespan. Gerontologists thus calculate that their prospects for increased public funding will be maximised by presenting their work in such a way as to dispel this fear. This is eminently sensible. What is more questionable is the legitimacy of overstating the case. Every gerontologist knows that frailty is the main cause of mortality, and also that frailty is intrinsically progressive; thus, extending lifespan without comparably extending healthspan (the Fukuyama scenario) is impossible, but so is the converse. Being frail is risky, being robust is not risky, and no amount of success in combating ageing will change that. Modest compression of morbidity has occurred in the past two decades in the USA, as documented most thoroughly by James Fries, ${ }^{3}$ the originator of the concept, ${ }^{4}$ but this has been entirely restricted to mild or modest as opposed to severe frailty and can (in my view) be explained mainly by education, as there is a strong correlation between health and level of education, and the education levels of elderly people rose substantially during this period. ${ }^{5}$ Thus, there is no basis for optimism that substantial further compression of morbidity will occur in the developed world, and certainly not as a result of progress in biogerontology. Yet, most senior gerontologists have no compunction in parading the goal of compressing morbidity-with a straight face, no lesswhenever a holder of purse strings hoves into view.

It seems to have escaped these gerontologists' notice, however, that this policy (which has been pursued for decades) has been an abysmal failure. Funding for basic research into the biology of ageing, let alone into how to combat it, remains pitiful, and even more pitiful when considered in light of the extraordinary degree of media exposure that gerontologists enjoy, which presumably reflects intense and sustained public interest in such work, something that politicians might a priori be expected to take into account.

A large part of the reason for this is doubtless that politicians do not believe what gerontologists tell them. First of all they "know" that ageing is immutable, and hence that such research is money down the drain. Secondly, they fear that if by chance progress were indeed made then the global nursing home scenario would duly result, despite gerontologists' protestations to the contrary. Thirdly, even if health were prolonged, they recognise that society would experience dramatic and unpredictable changes if lifespans were greatly increased, and unpredictability is not the politician's friend.

I will argue in this essay that this slavish pandering to what the gerontological establishment seem to think that its paymasters want to hear is not only a failed and misguided policy in terms of funding, but also an abdication of gerontologists' public duty as the people with the expertise and authority to point the way to a better world, one where humanity's foremost remaining scourge is no more. I will further argue that those with an appreciation of the depth of society's irrationality concerning curing ageing-among whom ethicists are, in my experience, heavily representedhave a similar duty to hasten the exposure of that irrationality and thereby bring it to an end.

\section{THE LEGITIMACY OF REPUGNANCE}

In 1997, Leon Kass published in the New Republic an essay entitled "The wisdom of repugnance" in which he presented his reasons for opposing human reproductive cloning. ${ }^{6}$ The essence of his argument is contained in this excerpt: 


\begin{abstract}
"Offensive." "Grotesque." "Revolting." "Repugnant." "Repulsive." These are the words most commonly heard regarding the prospect of human cloning. Such reactions come both from the man or woman in the street and from the intellectuals, from believers and atheists, from humanists and scientists. Even Dolly's creator has said he "would find it offensive" to clone a human being.
\end{abstract}

Revulsion is not an argument; and some of yesterday's repugnances are today calmly accepted - though, one must add, not always for the better. In crucial cases, however, repugnance is the emotional expression of deep wisdom, beyond reason's power fully to articulate it. Can anyone really give an argument fully adequate to the horror which is father-daughter incest (even with consent), or having sex with animals, or mutilating a corpse, or eating human flesh, or even just (just!) raping or murdering another human being? Would anybody's failure to give full rational justification for his or her revulsion at these practices make that revulsion ethically suspect? Not at all. On the contrary, we are suspicious of those who think that they can rationalize away our horror, say, by trying to explain the enormity of incest with arguments only about the genetic risks of in-breeding.

A common reaction to this passage, and to others like it, has been that it amounts to capitulation: that Kass is conceding that he has no articulable argument for his view, and thus that his view is irrational (the sort of view that only the uneducated masses are entitled to hold) and hence invalid. Now, in the interests of full disclosure I must declare at this point that I am, as Kass reveals himself above to be, a non-cognitivist: I feel that the more fashionable metaethical view that ethical opinions for which logical arguments have been earnestly sought without success are invalid makes the error of regarding ethics as like mathematics, with axioms and theorems, when in fact it is more like science, with data and hypotheses. However, I like to think that those who read this essay will be doing so more to discover my geronto-ethics than my meta-ethics, so I will elaborate on the latter elsewhere. What I wish to do here is to provide arguments that people in general, not only bioethicists, will find persuasive; one is unlikely to achieve that without an honest consideration of what they have found persuasive in the past. A flat rejection of Kass's noncognitivism as set out above fails to do this. It overlooks the indisputable facts that: (1) his espousal of that stance has not stopped him from becoming the bioethicist with by far the greatest influence in the real world today; and (2) this is not simply because he happens to have an acolyte in the White House, as that acolyte has just been decisively re-elected and his ethics are widely viewed as a large part of the reason why. As with art, many people apparently feel that, even though they do not know much about ethics they know what they dislike, and they show no sign of becoming ashamed of this any time soon, despite ethicists' best efforts.

For this reason, I will not attempt here to argue that the reason Kass is wrong is that he has failed to tell us cogently why he's right. Rather, I will demonstrate that, even within a noncognitivist world-view, ageing cannot be coherently defended in present-day society. Some of what I have to say has appeared in abbreviated form elsewhere. $^{7-9}$

\section{THE EVOLUTION OF REPUGNANCE}

A hint of the flaw in Kass's argument appears in the above passage. Some activities that used to be repugnant to most people are now largely agreed to be unexceptionable - for example, homosexuality. This is a case where what is repugnant to us now is the fact that we so recently felt that repugnance! Kass dodges this by describing those cases in which our attitudes have not changed as "crucial", but he conspicuously omits any discussion of what makes these cases crucial, leaving as his only criterion the circular observation that they have not changed.

If our moral instinct is self-defining, how can it change? I think the answer is clear, although perhaps surprising: we apply logic to it. Our non-acceptance of homosexuality was abandoned, it seems to me, because it was progressively seen to be inconsistent with other, even more central, aspects of our sense of right and wrong, such as the right to do what one likes when it does not harm others. I reiterate that I do not base this on the assumption that there is One True Morality, existing independently of humanity in the way that the laws of relativity are generally presumed to do. I mean only that the evolution of our morality over time seems-for whatever reason-reliably to follow a course of increasing internal consistency, and, in particular, when deviations from this consistency become too stark to ignore, ethical opinions that are more central tend to survive at the expense of less central ones. Why this should be so is a matter for psychologists, not ethicists; I merely observe that it reliably is so. There seems to be a generally felt need for the pragmatic resolution of ethical muddles and conflicts.

Note that the wary reader will immediately interject that this observation is useful (in the sense of giving rise to predictions of which ethical opinions will eventually win out in such situations) only if we base it on an objective measure of how central an ethical opinion is. I have such a measure in mind above: I define centralness in a graph-theoretical sense, where "more central" means more strongly connected to one's other ethical opinions-that is, possessing more overlap with those other opinions in respect of the frequency of scenarios that they state are good or bad.

This way of looking at the evolution of morality also illuminates the opposite transition, the emergence of popular repugnance at something that was once accepted. Kass largely avoids such cases (he makes no mention of slavery, for example), but not entirely: he does mention murder. I need not review how recently it was that those of European descent, when colonising distant lands, freely massacred indigenous populations; we all know our history all too well. Here, too, we came to appreciate the inconsistency of such attitudes with others that we (individually, and in due course as a society) found to be more central to our sense of right and wrong, and having done so we set aside our misguided ways. Again, I deliberately avoid discussion here of how we arrived at that original sense of right and wrong, and also of why we gravitated towards any resolution of its internal inconsistency at all; I merely note that when we did so our more central (by the above definition) views were the ones that prevailed, and I infer from this that a similar course of events may occur in comparable situations in the future.

\section{THE CONTROVERSIAL REPUGNANCE OF AGEING}

We can now return to the topic at hand-society's prevailing ambivalence towards curing ageing. I suggest that it is instructive to compare this situation with our past attitude towards other enterprises, in order to discover whether some developments about which we were once similarly cautious have since become firmly accepted as right and proper. If so, we must be open to the possibility that the same will happen 
with curing ageing. One example from recent western history stands out: women's suffrage. Before examining this, I must remind the reader that I am scrupulously avoiding any reliance on cognitivism here. Some may feel that women's rights campaigners were correct because their opponents could not articulate morally persuasive arguments why women were less entitled to vote than men, but to rely on that sort of reasoning is to assume that all possible such arguments were indeed raised at the time, and therefore to acknowledge that we may in due course realise that women should actually not have the vote if a much better argument for denying it to them is identified. At least when it comes to defeating ageing, I prefer to avoid acknowledging any such thing, because to do so is to offer apologists for ageing the retort that, just because they cannot articulate an argument for their position, that does not mean that no such argument exists. This is a retort that many who do not particularly pride themselves on their rhetorical skills are abundantly willing to offer.

Great Britain has for nearly three centuries been a democracy with a structure very similar to today's, but it was not until 1928 that voting rights for British men and women were equalised. This was the culmination of an effort that had been debated for a century in the media and, since 1851, even in parliament. A nearly identical timeframe saw the corresponding development in the USA. It is quite incomprehensible today how those who led such proud democracies during this period could have found it acceptable, let alone appropriate, to deny the vote to half their population. Perhaps the most incredible moment in this era was the emancipation of ex-slaves after the American Civil War (the 15th amendment to the US Constitution): that a government which had just fought a civil war to emancipate one group could rationalise the non-emancipation of a much larger group is something that, I think, only a historian can adequately explain. We can, however, review some of the arguments put forward in the late nineteenth century in favour of the status quo, often by women. Here are some examples from Helen Kendrick Johnson's Woman and the Republic, published in $1897::^{10}$

Aristocracy decrees that in the House of Lords the Bishops shall have a voice; but in the House of Commons no clergyman can hold a seat, and for members of Parliament no woman votes. Would any Suffragist hold that a clergyman was the inferior of men who do sit in the House of Commons? They are excluded for the same reason that woman has not the parliamentary vote - they are looked upon as noncombatants.

The countries where woman has full suffrage (save in the United States) are all dependencies of royalty. They are: The Isle of Man, Pitcairn's Island, New Zealand, and South Australia. The most important of these, New Zealand, was once a promising colony, but it has been declining for a quarter of a century.

The fact that the men of the family are the natural defenders of law, and the women are not, is seen at close quarters in the home, and in case of opposite votes and any serious resulting action, the father and son must stand in the attitude of actual physical as well as political antagonism to the mother and daughter.

As to the thousands of women who want the vote, there are some figures as to the majority that "are indifferent or even hostile." I see by the pamphlet published by the New York State Suffrage Association, that they have but 1,600 paying members, which is not one in a thousand of the women in the State over twenty years of age.

Comment on these arguments is pointless today, and we rejoice that it is (although I should again caution the reader that that does not necessarily mean we are right in any objective sense-that is, it does not necessarily make us cognitivists). Comparison with the more frequent arguments put forward against curing ageing, and thus in favour of denying potential beneficiaries of such a cure the even more fundamental right to avoid an unnecessarily early death, will be readily apparent, as both are stark examples of the naturalistic fallacy, the confusion of what is with what ought to be. However, as I noted above, the inadequacy of these arguments is (at least to the noncognitivist) only circumstantial evidence for the inadequacy of any possible argument, and the parallels with ageing thus merit further reinforcement.

\section{THE UNCONTROVERSIAL REPUGNANCE OF DENYING OTHERS THE CHOICE TO LIVE}

Having established that society can, eventually, identify and remedy shortcomings of its attitudes to fundamental aspects of its organisation, we can embark with at least a scrap of optimism on the construction of arguments that may hasten this in the case of curing ageing. I will here outline what I consider the most promising such argument. It has potential because it follows the approach set out earlier: it identifies values that are observed (not only reasoned) to be so central to the sense of right and wrong of most of presentday humanity that none of the arguments put forward in favour of ageing can match them. It thereby leaves, as the only remaining requirement for persuading someone that curing ageing is our duty, a way to keep our proageing interlocutor on the rational straight and narrow.

The argument in question concerns human rights, in particular the right of a healthy human being to carry on living. Throughout western Europe it has been appreciated for some decades now that even committing the most heinous of crimes does not cause one to forfeit this right; hence, not only has capital punishment been abolished but we do not even extradite people to nations that retain it if there is any threat that it would be used on them. The same seems to apply at international level: western European nations are approaching the 60th anniversary of the last time any of them were at war with each other, something that has not been seen since Roman times. We have somehow discovered that massive loss of life of our men and women in their prime is not easily justified in the interests of national pride.

I will assume here (which I feel able to do, since others have argued it very compellingly ${ }^{11}{ }^{12}$ ) that, for present purposes, there is no moral distinction between action and inaction, in particular between acting to shorten someone's life and not acting to extend it. The concept of a "duty of care" is a common expression of the view that there is little moral difference (albeit plenty of psychological difference) between action and inaction when it comes to prolonging or shortening life. A discussion of the ethical validity of this concept is beyond the scope of this essay; suffice it to say that the widespread legal concept of criminal negligence is a demonstration that most modern societies hold it dear. Since the present discussion concerns not absolute morality (if such a thing exists) but contemporary morality, this is all that is relevant here.

The applicability of these observations to the issue of curing ageing becomes apparent when we try to discern a difference between extending the healthy life of a young person and that of an old person. When a 10-year-old girl falls into a swollen stream and we rescue her, or when she is diagnosed 
with leukaemia and we cure her, it is customary to say that we saved her life. When we do this for a 50-year-old woman, we still say that. When we develop a vaccine for a new strain of influenza that is claiming thousands of lives per day and it is distributed and brings the pandemic under control, we again say that we have saved some (estimated) number of lives. (There is of course a distinction here between what a dead human's lifespan actually was and what a living one's may be, but that distinction applies equivalently across all these cases.) What, then, have we done when we develop and distribute a cure for ageing?

Opponents of curing ageing often suggest that this constitutes extending, rather than saving, their lives (and that extending lives is morally ambiguous even though saving lives is not). Let us then examine what difference there might be between extending lives and saving lives. I have occasionally been told that one is saving a life if the beneficiary is younger than the life expectancy of the population, but "only" extending it if not. It is easy to show that this or any similar distinction is absurd; I will give just one simple demonstration. First, one must choose the population. Should it be the global population? That of one's country? That of the country with the highest life expectancy? All seem equally defensible (or not), but if it is the second of these, one had better not get sick in Sierra Leone over the age of 40 . Even if we take a generous interpretation, such as the third alternative just given, we are neglecting the inherent heterogeneity within any population with respect to the rate of ageing. Jeanne Calment died in 1997 at the age of 122, older than any other reliably recorded human. It would be a brave ethicist who claimed today (knowing that she in fact lived to 122) that pulling her from a swollen river at the age of 85 would not have constituted saving her life.

In order to maintain my non-assumption of cognitivism, however, I must do more than dismantle specific arguments; I must show that it is impossible to argue that we have done anything meaningfully different when curing leukaemia and when postponing ageing. This is simple because it derives directly from the definitions of those concepts. In each circumstance we are giving the beneficiary a greater remaining healthy potential lifespan than they would have if we held back, which is the beginning and end of what we mean when we say we have saved their lives, and also of what we mean when we say we have extended their lives. This is not a matter of the absence of a contrary argument; it is a matter of definition, plain and simple. ${ }^{9}$

\section{SIMPLIFICATION OF EQUALITY WHEN AGEING IS, OR COULD SOON BE, TRULY CURED}

I will now address a highly relevant issue that cannot be overlooked in this context: finitude of resources. There is one quite cogent argument against expending limited medical resources on elderly people: by doing so one is diminishing the resources available to spend on young people, who have more to gain. Although there are certainly counter-arguments to this, they are by no means decisive, not in my mind, at least.

However, this issue does not in fact apply to the topic at hand. This is for the simple reason that a cure for ageing is just what it says: a removal of the inverse relation between how long one has lived so far and how much longer one is likely to live, even with the best medical care. When ageing is no more, there will simply be no physiological difference between older and younger adults. I find that this takes some time to sink in, so I encourage readers to perform a brief exercise: Step 1: think of a physiological difference between older and younger adults today. Step 2: imagine the older person being identical to the younger person in that respect. Carry on doing this until you stop saying to yourself "Oh, but of course he doesn't include this difference, clearly it would remain", because I do include that difference. Step 3: repeat from step 1 with a different difference. Fertility? No difference. Libido? No difference. Strength? You heard me. Putting it more formally: we readily see that life expectancy in Sierra Leone is a contingent fact, capable of being increased by ordinary means. What we evidently find much harder to see, but must, is that all human lifespans are likewise tractable.

In a post-ageing world, there is a word for discrimination on the basis of age in respect of the supply of medical care, a word with which we are already familiar: ageism. Ageism is already rather deeply understood to be wrong (although the implementation of this understanding in everyday life is, to be sure, still incomplete). Furthermore, the more fundamental the human right that is being denied to elderly people in favour of those who are young, the more wrong ageism is. Human rights do not get any more fundamental than the right to carry on living. (The issue of whether this right can legitimately be subdivided into: (1) a right to protection from harm; and (2) a right to enhancement, was addressed earlier, because this is identical to that of whether one can distinguish saving lives from extending lives.)

The final step in my argument addresses the distinction between treatments available today (but in limited quantity) and those that have not yet been developed, of which a cure for ageing is of course one. Some argue that it is more appropriate to invest resources in the provision of existing treatments (such as vaccines for African children) than in the possibly protracted quest for future ones. I suggest that this is like saying that killing people by putting a booby-trap bomb under their car is less bad than killing them with a gunbecause the interval between one's action and one's victim's death is longer; this is a comparison on which the law takes a rather uncompromising contrary view. (This analogy is valid because we are within striking distance of curing ageing, such that a year's vacillation today almost certainly delays the date at which such a cure is developed by at least a month, albeit probably not by a whole year.) Furthermore, given that a cure for ageing will confer a much greater increase in its beneficiaries' life expectancy than a cure for any disease can do in the absence of a cure for ageing (and that there will also be far more beneficiaries), a more accurate analogy would be the comparison between shooting one person and bombing a skyscraper; this is also true, albeit quantitatively less so, even if one regards the correct measure of the benefit of extending someone's life as the ratio, rather than the difference, of his or her remaining lifespan with versus without the intervention.

In concluding this section, I must again stress that the above argument should not be read as an attempt to show that ageing is objectively worse than anything that curing ageing might cause. I claim merely that our existing moral sense considers it as such implicitly but not explicitly, and that our rejection of the life-extension imperative results purely from our success in blinding ourselves to this internal inconsistency of our moral position. It is easy to see why we engage in this breathtaking self-deception: we find it the only effective coping strategy in the face of the ghastliness of ageing, since we remain convinced that ageing is inevitable. Now that ageing is within sight of not being inevitable, our collective hypnosis is no longer a solution but has become part of the problem; it is costing lives. Breaking our trance seems highly challenging, however. Forcing ourselves to confront this moral inconsistency is a promising way to banish the indefensible arguments that so 
many of us cleave to in order to preserve our view that ageing is actually a good thing.

\section{THE UTILITY OF AGEING TO BIOCONSERVATIVES}

I am currently in a minority (the leading edge, as I of course claim) within mainstream biogerontology in my view of the likely timeframe before we obtain a true cure for human ageing. Most of my colleagues are unwilling to go much further than Steven Austad, who has stated $^{13}$ that he thinks the first 150year-old was already alive by 2000 . Some now opine that drugs that can increase human life expectancy by up to 20-30 years may be developed within the next couple of decades, but they are coy when it comes to putting a probability on this and even more coy concerning the age at which one would have to start taking such drugs in order to achieve this benefit.

You would not guess this from the attention that the prospect of much more dramatic life extension has received from prominent bioethicists, especially from those on the bioconservative side of the fence. ${ }^{14}$ The notorious President's Council on Bioethics, chaired by Leon Kass, devoted extensive debating time to this matter during 2003, leading to an entire chapter (entitled "Ageless bodies") in their report published early in $2004 .^{15}$

The reason that Kass has put forward $^{16}$ for this curious concern is, in a nutshell, that he does not believe those biogerontologists who aver that 20-30 years is the absolute maximum that we could obtain, not only from the foreseeable approaches currently fashionable in mainstream gerontology but also from any unforeseen approaches that have any chance of being developed in the next several decades. This is not because he has read my publications on the subject, nor any similar literature-at least, he has not said publicly that he has-but rather because he claims that science is a progress-driven enterprise. Twenty to 30 years may (arguably) be of little importance in bioethical terms, but it will be plenty in terms of sweeping away our current acceptance that ageing is immutable, and the resulting increase in scientists' motivation to identify new and ingenious ways to do much more will (Kass asserts) quite probably bear fruit, as has occurred in so many other fields of technological endeavour in the past.

Although I entirely agree with this argument, I suspect that it is not the true reason why Kass and his followers are so interested in extreme life extension. They may have convinced themselves that it is, and indeed one would be hard put to challenge its logical force, but I feel it is much more likely that the bioconservatives do not, in fact, believe that even a 20-30-year rise in life expectancy is all that close, any more than do the politicians and funding agencies who allocate basic biogerontology such pitiful funding. Rather, I think they calculate-perhaps unconsciously, I repeat-that the "menacing spectre of immortality" (as the eminent biogerontologist Leonard Guarente so outrageously described it in his recent book $^{17}$ ) is an issue on which they have the public somewhat on their side from the outset; it is thus a device to obtain a foothold in people's minds via which to propagate their much more unpopular views on present-day or imminent biomedical technology. ${ }^{18}$ All the more reason, then, to awaken the public from its collective, mutuallyreinforced trance concerning life extension, and thereby to deny bioconservatives this psychological tactic for perpetuating a policy on other biotechnology that is costing so many lives.

\section{CONCLUSION: CONSCIENTIOUS BIOETHICISTS CAN SAVE THE WORLD}

The ostensible goal of science and scientists is to advance our understanding of nature as fast as possible. In practice, however, many of the tendencies that the career structure of science rewards are powerfully opposed to this goal. In particular, there is a profound disincentive to challenge the conclusions of one's senior colleagues unless and until the evidence with which one can do so is totally overwhelming. The result is that cogent challenges to established dogma often go unstated. Worse yet, when those challenges are made, the establishment position is often not publicly defended but merely asserted anonymously, on account of the establishment's reluctance to give publicity to debates that might undermine it.

Ethicists, like others in the humanities, do not suffer this problem, for the simple reason that the provision of opinion and mutual critique (as opposed to experimental data) is precisely their raison d'être. They, therefore, can cut through the political inertia that so often strangles scientific progress. Clear statements concerning the logical shortcomings of the major prevailing arguments against curing ageing as soon as possible can make a real difference here, breaking the trance of approval of ageing under which humanity has so powerfully held itself as a coping strategy in the face of ageing's perceived inevitability. Such statements cannot be relied upon to issue from the scientists best placed to give them urgency, but they can be given urgency nonetheless. It is thus quite possible that ethicists will accelerate the progress of science in this field by a greater degree than they have done for any other field since their own discipline was founded, so many millennia ago. The fact that the cure of ageing will be the greatest achievement of science since it was founded is, perhaps, no coincidence.

\section{ACKNOWLEDGEMENTS}

I am much indebted to Steven Horrobin and John Harris for extensive and highly valuable comments on earlier drafts.

$J$ Med Ethics 2005;31:659-663.

doi: 10.1136/jme.2005.011957

Correspondence to: A D N J de Grey Department of Genetics, University of Cambridge, Downing Street, Cambridge CB2 3EH, UK; ag24@gen.cam.ac.uk

Received 16 February 2005

Accepted for publication 16 February 2005

Competing interests: none declared

\section{REFERENCES}

1 Anonymous. Motto of the Gerontological Society of America. J Gerontol 1946;1:cover.

2 Fukuyama F. Our posthuman future: consequences of the biotechnology revolution. New York: Picador, 2002.

3 Fries JF. Measuring and monitoring success in compressing morbidity. Ann Intern Med 2003;139:455-9.

4 Fries JF. Aging, natural death, and the compression of morbidity. N Engl J Med 1980;303:130-5.

5 Bandura A. Health promotion from the perspective of social cognitive theory. In: Norman $\mathrm{P}$, et al., eds. Understanding and changing health and behaviour. Reading: Harwood, 2000:299-339.

6 Kass LR. The wisdom of repugnance. New Republic 1997;216(22):17-26.

7 de Grey ADNJ. Leon Kass: quite substantially right. Rejuvenation Res 2004;7:89-91.

8 Horrobin S. A critical survey of the bioethical components of the International Association of Biomedical Gerontology 10th Congress, September 2003. Bioethics, 2005, in press.

9 de Grey ADNJ. Three self-evident life-extension truths. Rejuvenation Res 2004;7:165-7.

10 Johnson HK. Woman and the Republic. New York: Guidon Club, 1897.

11 Harris JM. Violence and responsibility. London: Routledge, 1980.

12 Glover G. Causing death and saving lives. Harmondsworth: Penguin, 1977.

13 McCann J. Wanna bet? Scientist 2001;15:8.

14 Perry D. Someone's knocking on the laboratory door. Rejuvenation Res 2004;7:49-52.

15 President's Council on Bioethics; Kass L. chair. Beyond therapy: biotechnology and the pursuit of happiness. Washington DC: President's Council on Bioethics, 2003.

16 de Grey ADNJ. Escape velocity: why the prospect of extreme life extension matters now. PLoS Biol 2004;2:723-6.

17 Guarente L. Ageless quest. New York: Cold Spring Harbor Laboratory Press, 2003.

18 Perry D. Science and politics: world events intensify stem cell debate. Rejuvenation Res 2004;7:223-5. 